\title{
Chapter 5 \\ Experimental Re-creation \\ of the Depositional Context in Which Late \\ Pleistocene Tracks Were Found \\ on the Pacific Coast of Canada
}

\author{
Duncan McLaren, Quentin Mackie, and Daryl Fedje
}

\begin{abstract}
To better understand the depositional context of Late Pleistocene human tracks found at archaeology site EjTa-4 on Calvert Island, on the Pacific Coast of Canada, we present here the results of an experiment designed to recreate the conditions by which these tracks were formed, preserved and then revealed through excavation. Based on radiocarbon ages on small twigs and the analysis of sediments and microfossils, the interpretation of the site formation processes relate that the tracks were impressed into a clayey soil substrate just above the high tide line between 13,317 and 12,633 calBP. The features were subsequently encapsulated by black sand, which washed over the tracks from the nearby intertidal zone during a storm event. To test this interpretation, we enlisted the aid of high school student volunteers to recreate the conditions by which the tracks were formed. A clayey substrate was prepared in a laboratory setting at the University of Victoria and a few plant macrofossils were placed on top it. This was followed by having the students create tracks in the clay, which were then covered with a layer of sand. Upon excavation of these experimental tracks, we found that they had a very similar character to those found in the field, including the pressing of macrofossils into the clay by the weight of the track maker. These results support the interpretation and chronological assessment of the depositional events that occurred during late Pleistocene times at archaeology site EjTa-4.
\end{abstract}

Keywords Footprint $\cdot$ Experimentation $\cdot$ Open air $\cdot$ Monitoring

D. McLaren $(\bowtie) \cdot$ D. Fedje

Hakai Institute, Campbell River, BC, Canada

University of Victoria, Victoria, BC, Canada

e-mail: dsmclaren@gmail.com

Q. Mackie

University of Victoria, Victoria, BC, Canada

(C) The Author(s) 2021

A. Pastoors, T. Lenssen-Erz (eds.), Reading Prehistoric Human Tracks, https://doi.org/10.1007/978-3-030-60406-6_5 


\section{Introduction}

This paper follows up on archaeological findings of human tracks dating to the Late Pleistocene occupation of the Pacific coast of Canada (McLaren et al. 2018) (Fig. 5.1). These tracks were found in soft sediments beneath intertidal beach deposits on Calvert Island, British Columbia. A total of 29 tracks were identified and isolated during the excavation of a $4 \times 2 \mathrm{~m}$ area at archaeological site EjTa-4 (Meay Channel I). Lodgepole pine twigs found on the track surface and pressed into the base of the footprint (referred to here as the true track) provide us with radiocarbon age estimates of 13,317-12,633 calBP (see Marty et al. 2009; Bennett and Morse 2014 for definition of track terms).

Archaeological site EjTa-4 is located on the western shore of Meay Channel, an inner and protected waterway situated between Calvert and Hecate Islands. Calvert Island features as a location in events related in the oral histories of the Heiltsuk (Olson 1955) and Wuikinuxv First Nations (Walkus et al. 1982). Some of the recorded oral histories from the region relate events, such as large-scale glaciation, that have not occurred since Late Pleistocene times (Gauvreau and McLaren 2016).

Ancient human track sites have not been widely reported in North America north of Mexico. There are some exceptions. For example, a recent publication describes a Late Pleistocene trackway in New Mexico which has associated human and giant ground sloth footprints dating between 15,500- and 10,000-year-old (Bustos et al. 2018). Willey et al. (2009) provide a summary of Holocene human footprints reported from North America, with a more recent discovery reported from Swan

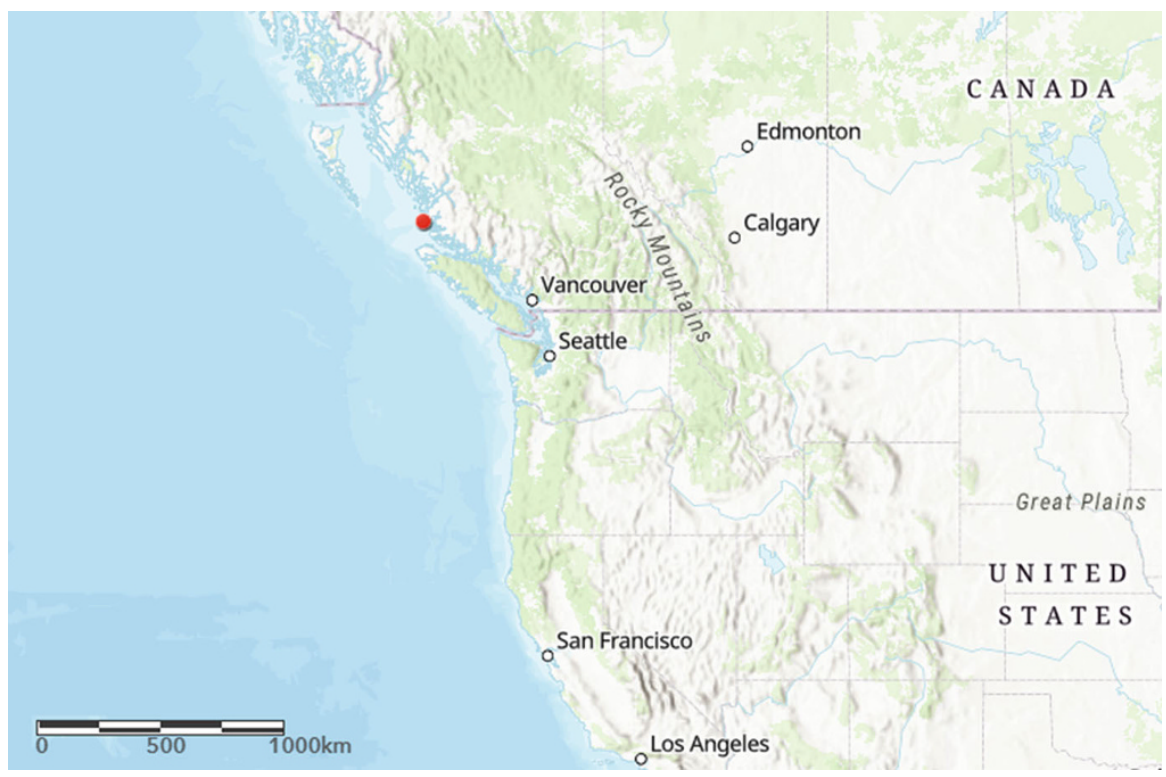

Fig. 5.1 Location of archaeological site EjTa-4 on the Pacific coast of Canada 
Point Alaska dated to 1840 calBP (Smith et al. 2019). Overall, however, human tracks appear to be an extremely rare site type across the continent.

Nearshore Late Pleistocene archaeological research on west coast of Canada requires a good knowledge of local relative sea level history (Clague et al. 1982; Fedje and Mathewes 2005; Fedje et al. 2018; Shugar et al. 2014). Due primarily to the dynamic interplay of isostatic and eustatic factors, sea level on Calvert Island was 2-3 m lower than today between 14,000 and 11,000 years ago (McLaren et al. 2014). The tracks at this site were discovered during subsurface testing below beach deposits. This subsurface testing was specifically targeting this lower shoreline and time period. However, we were not expecting to find human tracks.

Of the 29 individual tracks found, 18 were complete enough to take measurements of length and width (McLaren et al. 2018). These measurements fall into three broad categories of size $(15.5 \times 7 ; 20 \times 9$; and $25.5 \times 11.5 \mathrm{~cm})$, suggesting that a minimum of three individuals of different foot sizes left the tracks. The majority of tracks were found to be oriented towards the northwest or landward and away from the ocean. A few rough grained stone tools were found in the same stratigraphic layer.

The track surface is a light brown clayey paleosol that was located above the high tide line at the time of deposition (referred to as Stratum X). It is overlain by black pebbly sand which was washed up from the beach filling the tracks (Stratum IX). Based on our analyses of these strata, we interpret that the formation of these features involved a minimum of three people leaving footprints in a clayey area above the high tide line between 13,317 and 12,633 calBP. Later, by at least 12,640-12,576 calBP, a change in sea level, storm surge or tsunami event resulted in the dumping of sand and pea gravel onto the track surface thereby filling and capping the features. Overlying all of this are sandy gravels with late Holocene artefacts and bone (Strata VII through II), capped at the top by active sands just below the beach surface (Stratum I).

The contrasting colours between the track surface and the over track deposits enabled us to identify the true tracks. As our field crew excavated down through the black sand deposits into the more clayey deposits below, sediment displacement rims were the first indicators found (Fig. 5.2). Through careful and delicate excavation, the sediment rims were isolated revealing the tracks. In some cases, toe marks were clearly visible. Photographs were taken of each of the individual tracks, and contrast enhancement software was used to further reveal the features for publication (Fig. 5.3). Multiple photos of all the tracks found are included in the supplemental data that is associated with the original publication (McLaren et al. 2018).

Beyond providing information on the inhabitants that made these tracks, the findings are of significance as they have bearing on the Late Pleistocene occupation of North America. This is one of the earliest human occupational records on the Pacific coast of Canada and provides evidence of the early postglacial use of this part of the coast. Those who left the footprints at EjTa-4 could only have reached Calvert Island by means of watercraft. These inhabitants most likely had an economy that was heavily focussed on the marine environment, as did later populations in the region (Duffield 2017). 


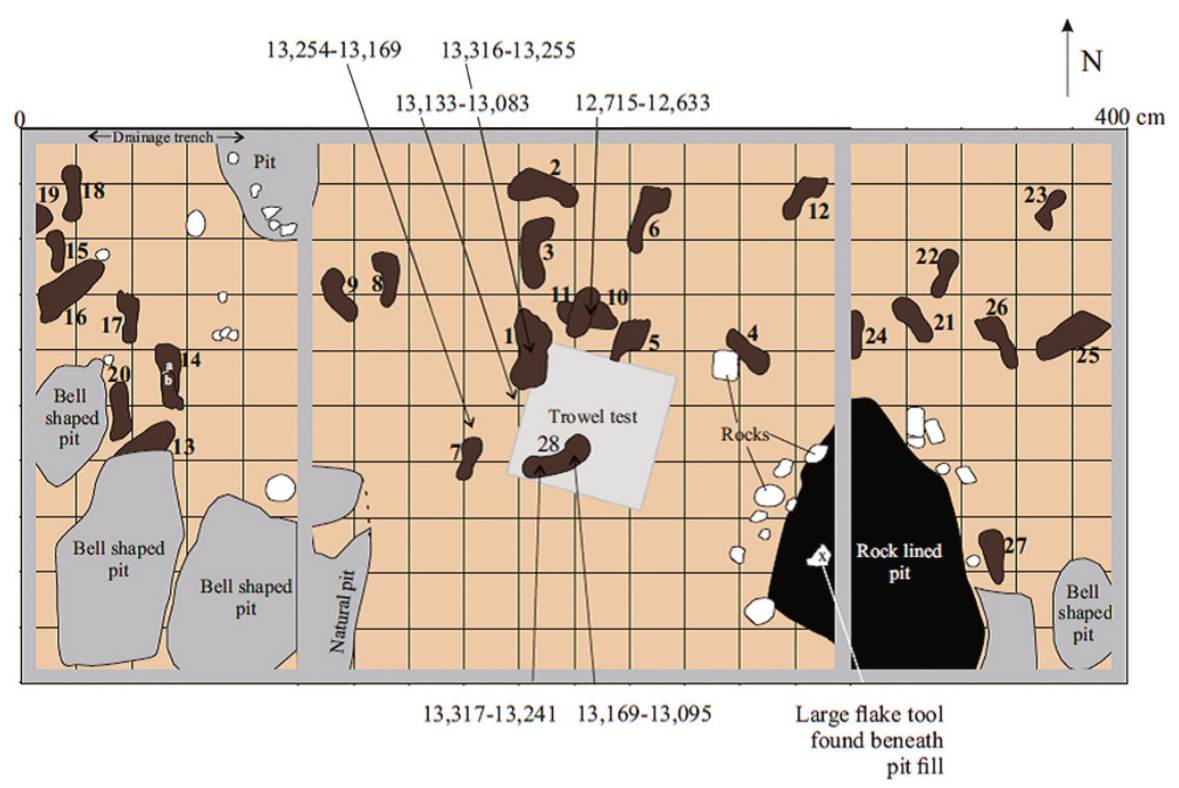

Fig. 5.2 Plan view of $4 \times 2 \mathrm{~m}$ excavation unit and the locations and orientation of tracks and radiocarbon dates

As a part of the ongoing research associated with the discovery of these tracks, we undertook a lab-based experiment to see if we could recreate the sedimentary conditions in which the tracks were created and then buried. As a part of this process, the experimental footprints were excavated to compare our field findings with those in the lab. This primary goal of the exercise was to help understand if our site formation process interpretation was supported by experimental approach.

As a part of informing the public about aspects of our research, we have been working with school groups from local communities including Bella Bella, Oweekeno Village, Bella Coola as well as in and around Victoria, British Columbia. The experiments discussed here were conducted as part of the Let's Talk Science Program undertaken with high school students at the University of Victoria.

Experimental track re-creations have been used by a number of researchers to help understand the processes by which ancient tracks were created from different perspective. For example, Ruiz and Torices (2013) used experiments to help determine speed estimations for human trackways. Marty et al. (2009) created tracks in a number of different contexts to help determine differences in morphology and taphonomy. 
Fig. 5.3 Examples of images taken of tracks that were excavated
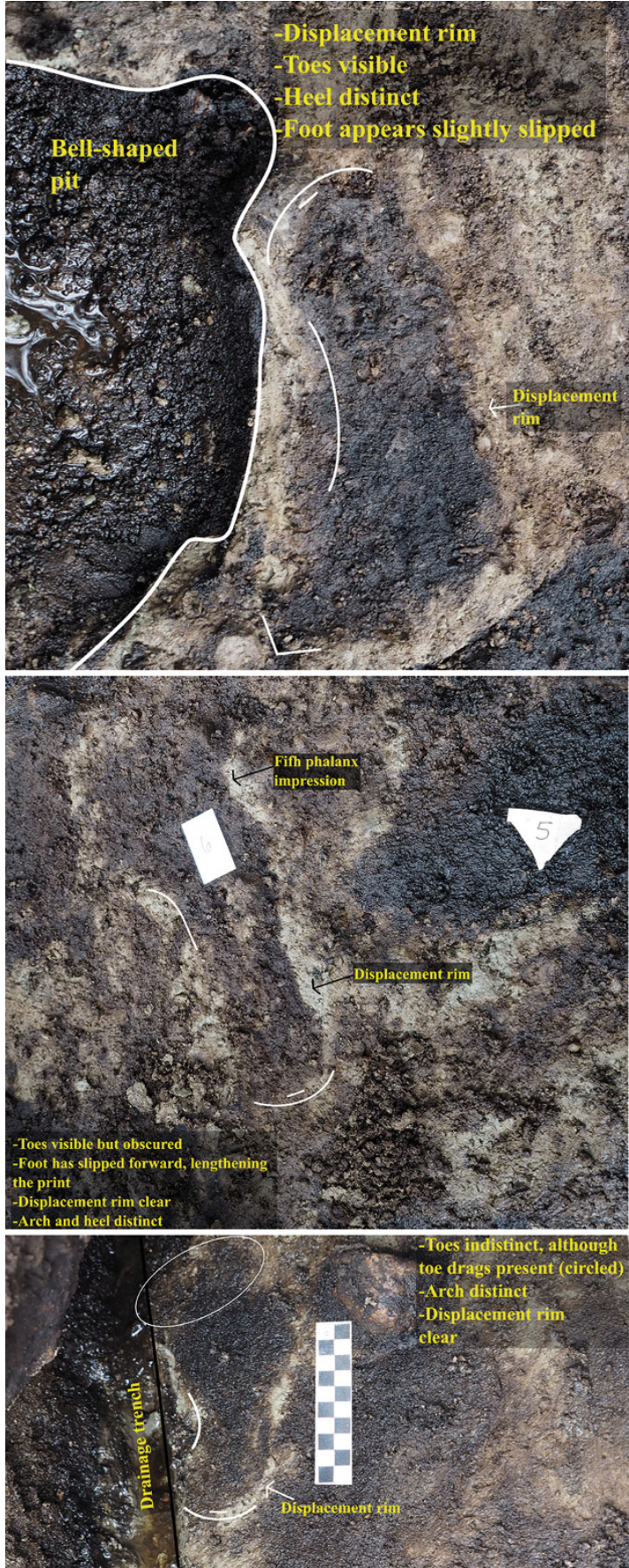


\section{Methods}

The experimental re-creation of the tracks from EjTa-4 was conducted during educational outreach sessions at the University of Victoria led by Duncan McLaren and Quentin Mackie. The experiment was run a total of four times with the help of high school students whose feet were used to make the footprints and University student volunteers who helped with setting up and monitoring the experiments (Fig. 5.4).

A clay matrix was specially prepared for this experiment. This clay included some fine potter's sand (less than $5 \%$ ) to give it some stiffness. The clay was pounded until consistent and then was placed in plastic totes to help keep it wet. Small twigs and leaf fragments were then placed on top of the clay substrate. High school students were then asked to volunteer to step into the clay to make a track. The following task involved adding dark grey coarse sand to cover the track and clay surface completely. The top of the sand was tapped gently to pack it down. The subsequent excavation of these features was undertaken by trowel and spoon.

Fig. 5.4 Experimental tracks created in clay during workshop on footprints at the University of Victoria

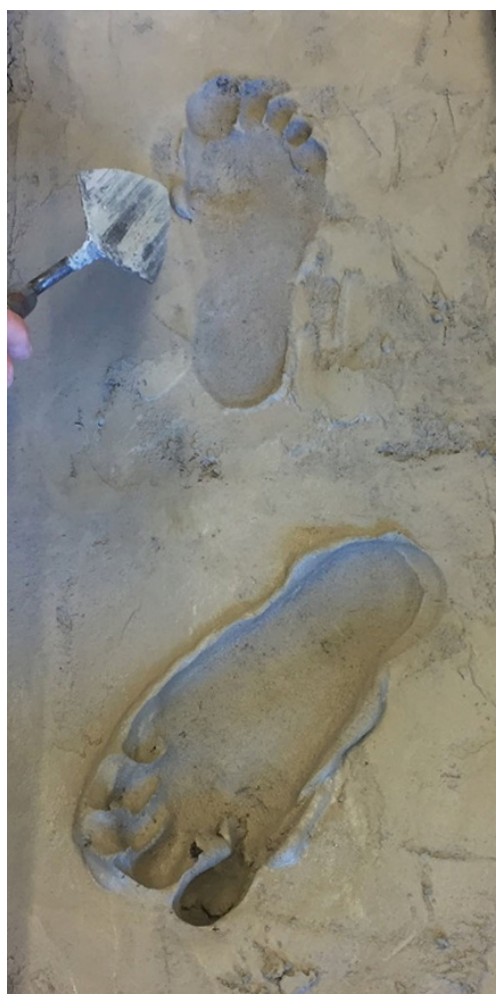




\section{Results}

The experiment was run a total of four times with four different high school student groups. Before covering the tracks with sand, we noted that the experimental clay matrices held the track impression well, being supported and shaped with the aid of the elasticity of the clay matrix. Sediment displacement rims were clearly visible, but were not necessarily created around the entire track. The feet of all of students were covered in the clay matrices after having completed making the track suggesting that at least some of the true track surface stuck to the bottom and sides of the foot.

Toe prints were visible in all cases, and some had sediment displacement rims between the individual toes. Sediment displacement rims were most prominent between the first and second toes. In one case, toe drag marks were left, and in another the heel had notably slipped towards the anterior.

With the addition of a layer of sand, the experimental tracks were rendered buried. The subsequent excavation of these tracks revealed that the sediment displacement rims were the first part of each track encountered (Fig. 5.5). Through further excavation, the remains of the true track could be revealed, providing a feature that could be measured. The twigs and leaves that had been left on top of the clay prior to impressing the track were impressed into the true track and in all instances needed to be removed from the clayey substrate below. All plant macrofossils recovered were covered in the clay.
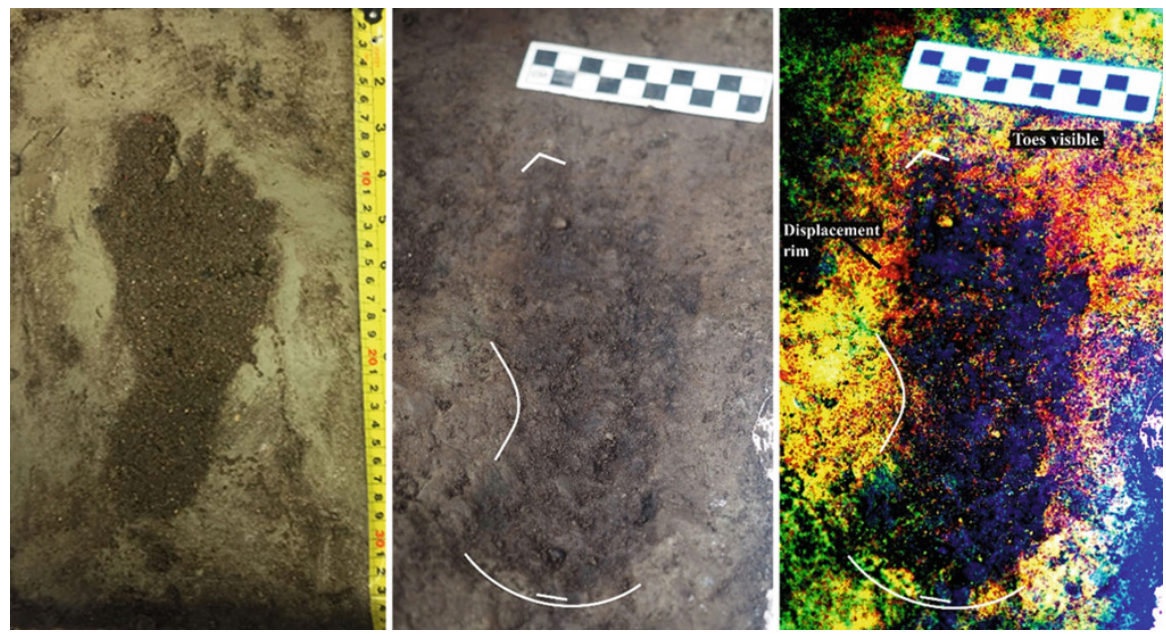

Fig. 5.5 Experiment track after excavation (left) compared with ancient track after excavation (centre) and image contrast adjustment (right) 


\section{Discussion and Conclusions}

The results of this experimental re-creation help inform us about the site formation processes of the tracks at archaeological site EjTa-4. The clayey matrix in which the experimental tracks were created was found to be an excellent substrate to create and hold the impressions that were made. This appears to have been somewhat dependent on the amount of moisture. By extension, with too much moisture, the tracks would have been soupy and would have quickly disappeared, and with too little moisture, a track impression would not have been as clearly made. From this we have learned that the conditions at EjTa-4 would have been fairly damp, but not too wet to create conditions whereby the tracks found were initially made. This is consistent with our interpretation of the original depositional context being immediately supratidal.

During the excavation of the tracks at EjTa-4, we found that the presence and identification of the sediment displacement rims was key to the initial identification of the tracks found. In the experimental footprints, sediment displacement rims featured prominently in the tracks that were created and were prominent enough to be the first attribute encountered during excavation.

In the experimental re-creations, toe impressions were clearly visible. These remained fairly distinct even after being covered with sand and then excavated. Similarly, toe impressions were found during excavations at EjTa-4 suggesting similarities in site formation process. Details such as these toe marks are important as they reveal that we are dealing with true track impressions as opposed to undertrack deposits which lack this type of detail (Marty et al. 2009).

Of particular importance to the chronological interpretation of the tracks at EjTa4 are the twigs that were found pressed into the true track surface. On the basis of the stratigraphic position of these twigs and the associated radiocarbon dates, we were able to assess that they were created between 13,317 and 12,633 calBP. The replication of this situation in the lab with the experimental true track surfaces having plant macrofossils pressed into them lends credence to our interpretation of the track formation process and chronology.

Based on our findings, we think that it is most likely that the tracks at EjTa-4 were buried relatively quickly after they had been created. We are not certain how long the track impressions would have lasted had they not been filled with sand. With an increase of the amount of time that the tracks were exposed it is likely that they would have washed to mush in a rain event, dried and desiccated beyond recognition during a dry period, or eventually would have become over trampled by other humans or animals. However, as the tracks were pressed into clay, it is possible that they would have retained their shape longer than tracks pressed into sand. As with most ancient track sites, it seems to be a fortuitous set of circumstances that resulted in the preservation of the features at all.

Overall, the experiment re-creation of tracks lends support to our interpretation of the site formation processes at EjTa-4. A minimum of three people left tracks just above the high tide line 13,000 years ago. These tracks were then covered by sand 
deposited in a high sea level event and remained capped since this time. While most track sites are revealed to archaeologists through erosion, those discovered at EjTa-4 were found through careful excavation. A key to the successful excavation of these tracks was the identification of sediment displacement rims which alerted the excavators to the likelihood that a full track lay beneath.

Acknowledgements The high school participants in the Let's Talk Science workshops where the experimental tracks were made are thanked. Katie Brynjolfson and Isabelle Rutherford, University of Victoria undergraduate volunteers, are thanked for their help in helping with the experiment reported on here. Stephanie Calce helped to organize the Let's Talk Science event for the Anthropology Department at the University of Victoria. George Mackie is thanked for preparing and pounding the clay and advice on sand and moisture content.

\section{References}

Bennett, M. R., \& Morse, S. A. (2014). Human footprints: Fossilised locomotion? Cham: Springer International Publishing. https://doi.org/10.1007/978-3-319-08572-2.

Bustos, D., Jakeway, J., Urban, T. M., Holliday, V. T., Fenerty, B., Raichlen, D. A., Budka, M., et al. (2018). Footprints preserve terminal Pleistocene hunt? Human-sloth interactions in North America. Science Advances, 4(4), eaar7621-eaar7621.

Clague, J., Harper, J., Hebda, R., \& Howes, D. (1982). Late quaternary sea levels and crustal movements, Coastal British Columbia. Canadian Journal of Earth Sciences, 19(3), 597-618. https://doi.org/10.1139/e82-048.

Duffield, S. E. E. (2017). Long-term use of fish and shellfish resources revealed through vibracore Sampling at EjTa-13, Hecate Island, Central Coast, BC. Unpubl. MA Thesis, University of Victoria. https://dspace.library.uvic.ca//handle/1828/8936. Accessed 8 Jan 2020.

Fedje, D. W., \& Mathewes, R. W. (Eds.). (2005). Haida Gwaii: Human history and environment from the time of loon to the time of the iron people. Vancouver: UBC Press.

Fedje, D., McLaren, D., James, T. S., Mackie, Q., Mackie, A. P., Smith, N. F., \& Southon, J. R. (2018). A revised sea level history for the Northern Strait of Georgia, British Columbia, Canada. Quaternary Science Reviews, 192, 300-316.

Gauvreau, A., \& McLaren, D. (2016). Stratigraphy and storytelling: Imbricating indigenous oral narratives and archaeology on the Northwest Coast of North America. Hunter Gatherer Research, 2, 303-325.

Marty, D., Strasser, A., \& Meyer, C. A. (2009). Formation and taphonomy of human footprints in microbial mats of present-day tidal-flat environments: Implications for the study of fossil footprints. Ichnos, 16(1-2), 127-142.

McLaren, D., Fedje, D., Hay, M. B., Mackie, Q., Walker, I. J., Shugar, D. H., Eamer, J. B. R., Lian, O. B., \& Neudorf, C. (2014). A post-glacial sea level hinge on the Central Pacific Coast of Canada. Quaternary Science Reviews, 97, 148-169.

McLaren, D., Fedje, D., Dyck, A., Mackie, Q., Gauvreau, A., \& Cohen, J. (2018). Terminal Pleistocene epoch human footprints from the Pacific Coast of Canada. PLoS One, 13(3), $\mathrm{e} 0193522-\mathrm{e} 0193522$.

Olson, R. (1955). Notes on the Bella Bella Kwakiutl. University of California Anthropological Records, 14(5), 319-348.

Ruiz, J., \& Torices, A. (2013). Humans running at stadiums and beaches and the accuracy of speed estimations from fossil trackways. Ichnos, 20(1), 31-35. 
Shugar, D. H., Walker, I. J., Lian, O. B. J., Eamer, B. R., Neudorf, C., McLaren, D., \& Fedje, D. (2014). Post-glacial sea-level change along the Pacific Coast of North America. Quaternary Science Reviews, 97, 170-192.

Smith, G. M., Parsons, T., Harrod, R. P., Holmes, C. E., Reuther, J. D., \& Potter, B. A. (2019). A track in the Tanana: Forensic analysis of a Late Holocene footprint from Central Alaska. Journal of Archaeological Science: Reports, 24, 900-912.

Walkus, S., Hilton, S. S., Walkus Windsor, E., \& Rath, J. C. (1982). Oowekeeno Oral Traditions as told by the Late Chief Simon Walkus, Sr. (Mercury Series No. 84). Ottawa: National Museums of Canada.

Willey, P., Watson, P., Crothers, G., \& Stolen, J. (2009). Holocene human footprints in North America. Ichnos, 16, 70-75.

Open Access This chapter is licensed under the terms of the Creative Commons Attribution 4.0 International License (http://creativecommons.org/licenses/by/4.0/), which permits use, sharing, adaptation, distribution and reproduction in any medium or format, as long as you give appropriate credit to the original author(s) and the source, provide a link to the Creative Commons license and indicate if changes were made.

The images or other third party material in this chapter are included in the chapter's Creative Commons license, unless indicated otherwise in a credit line to the material. If material is not included in the chapter's Creative Commons license and your intended use is not permitted by statutory regulation or exceeds the permitted use, you will need to obtain permission directly from the copyright holder. 